\title{
Risk factors for fracture redisplacement after reduction and cast immobilization of displaced distal radius fractures in children: a meta-analysis
}

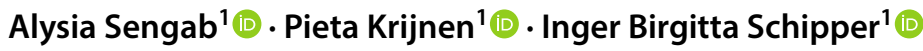

Received: 12 May 2019 / Accepted: 31 August 2019 / Published online: 9 September 2019

(c) The Author(s) 2019

\begin{abstract}
Purpose Displaced distal radius fractures in children are common and often reduced if necessary and immobilized in cast. Still, fracture redisplacement frequently occurs. This can be prevented by fixation of fracture fragments with K-wires, but until now, there are no clear guidelines for treatment with primary K-wire fixation. This meta-analysis aimed to identify risk factors for redisplacement after reduction and cast immobilization of displaced distal radius fractures in children, and thereby determine which children will benefit most of primary additional K-wire fixation.

Methods Eight databases were searched to identify studies and extract data on the incidence of and risk factors for redisplacement of distal radius fractures after initial reduction and cast immobilization in children.

Results Twelve studies, including 1256 patients, showed that initial complete displacement (odds ratio [OR] 4.69, 95\% confidence interval [CI] 2.98-7.39) and presence of a both-bone fracture (OR 1.95, 95\% CI 1.34-2.85) were independent risk factors for redisplacement. Anatomical reduction reduced the redisplacement risk (OR 0.14, 95\% CI 0.05-0.40). No significant influence on redisplacement risk could be established for female sex, experience level of the attending surgeon, Cast Index $<0.8$, Three-Point Index $<0.8$ and patient's age.

Conclusions For children with a displaced distal radius fracture, the presence of a both-bone fracture, complete displacement of the distal radius and non-anatomical reduction are risk factors for redisplacement after reduction of their initially displaced distal radius fracture. Children with one or more of these risk factors probably benefit most of reduction combined with primary K-wire fixation.
\end{abstract}

Keywords Radius fracture · Paediatrics · Displacement · Redisplacement $\cdot$ Risk factors · Cast immobilization · Cast index · Three-point index

\section{Introduction}

Distal radius fractures account for up to $35 \%$ of all paediatric fractures and are mostly caused by a fall on the outstretched hand or direct blow to the arm [1-4]. For substantially displaced paediatric distal radius fractures, fracture reduction and cast immobilization is often the treatment of choice. Recent studies showed, however, that redisplacement rates are considerable and range from 21 to $39 \%$ after conservative

Alysia Sengab

a.sengab@lumc.nl

1 Department of Trauma Surgery, Leiden University Medical Centre, Post Zone K6-R, P.O. Box 9600, 2300 RC Leiden, The Netherlands treatment [5-9]. To prevent redisplacement after reduction, the fracture can be fixated with K-wires. However, this treatment also has disadvantages as it can lead to complications such as pin-tract infection, neuropraxia and premature closure of the physis [10-14]. Therefore, it is important to balance advantages and disadvantages of non-operative and operative treatment in relation to the risk of redisplacement and its effect on final outcome. Many studies have been performed to identify risk factors for redisplacement showing varying results. Several studies recommended additional $\mathrm{K}$-wire fixation for not optimally reduced distal radius fractures, while others recommended additional K-wire fixation for all completely displaced fractures, even after an acceptable closed reduction [7, 9, 15, 16]. More recently, the quality of cast moulding was evaluated as a potential risk factor for redisplacement, however, without univocal results $[5$, 
17-19]. The aim of this meta-analysis was to evaluate the available literature on risk factors for redisplacement of distal radius fractures in children treated with reduction and cast immobilization, and thereby determine which children will benefit the most of primary $\mathrm{K}$-wire fixation additional to cast immobilization. This will aid in establishing guidelines for the treatment of displaced distal radius fractures with primary K-wire fixation.

\section{Materials and methods}

This meta-analysis was performed according to the preferred reporting items for systematic reviews and meta-analyses (PRISMA) guidelines [20].

\section{Search strategy}

A literature search was performed in PubMed, Embase, Web of Science, Cochrane, CENTRAL, CINAHL, Academic Search Premier and Science Direct on April 12th, 2019. The search strategy was composed by an experienced medical librarian. It included different synonyms of the keywords Radius Fractures, Child, Displaced, Casts and Risk Factors.

\section{Study selection}

Articles were selected if they (1) included skeletally immature patients, (2) that had a displaced distal radius fracture (with or without a concomitant distal ulnar fracture) requiring fracture reduction, (3) and were treated with above- or below-elbow cast immobilization. Articles had to be written in English and describe risk factors for redisplacement. Because definitions for displacement and redisplacement vary amongst studies, no predefined definition was applied for study selection, but only studies with commonly used and comparable definitions for (re)displacement (Table 1) were included in the meta-analysis. An additional criterion was that the articles reported odds ratios (ORs) of the risk factors for redisplacement, or provided sufficient information to calculate the ORs. Articles were excluded if these (1) concerned Salter Harris 3 and/or 4 fractures (as these usually require surgical treatment), (2) were case reports, reviews, conference abstracts, letters to the editor or cadaver studies, (3) also analysed other forearm fractures or treatment options, and the results for the displaced distal radius fractures treated with cast immobilization could not be extracted separately, or (4) reported only on potential risk factors that were not reported in one of the other included articles. Reference lists of the potentially relevant full-text articles were searched for additional eligible studies, which were included if the above-mentioned inclusion criteria applied. Study selection, data extraction and assessment of risk of bias were performed by two reviewers (AS and PK). Disagreement was resolved by discussion.

\section{Data extraction}

From the included articles, data were extracted on study characteristics (author, publication year, type of study), number of included patients, mean age, fracture characteristics (isolated distal radius or both-bone fracture), definition of indications for fracture reduction and redisplacement, type of anaesthesia and treatment (conscious sedation or general anaesthesia, closed reduction and cast immobilization or additional K-wire fixation, above- or below-elbow cast), outcome (redisplacement rate), and risk factors (age, gender, isolated radius fracture or both-bone fracture, complete displacement, quality of reduction, Cast Index, Three-Point Index, surgeon's level of experience). The definitions for redisplacement and indications for reduction are reported in Table 1. The calculation of the Cast Index and the ThreePoint Index is illustrated in Fig. 1. Optimal values for both indexes are considered below $0.8[5,18,19]$. A previous meta-analysis, published by Hendrickx et al. and Van den Bekerom et al., showed no significant difference in redisplacement rate after treatment with either above- or belowelbow cast immobilization [21,22]. Therefore, the type of cast (above or below elbow) was not included in the risk factor analysis.

\section{Statistical analysis}

A meta-analysis using Review Manager 5.3 was performed for the selected studies that applied similar data definitions and had comparable study groups. When available, results from multivariate analysis were used instead of univariate analysis. ORs were pooled using the generic inverse variance. The random-effects model was used for all meta-analysis. Statistical heterogeneity between studies was assumed if $p<0.10$ for the Cochran's Chi-square test or $\mathrm{I}^{2}>50 \%$ [23].

\section{Risk of bias}

Risk of bias in the included studies was assessed according to the 'Quality in Prognosis Studies' (QUIPS) tool as low, moderate or high in six domains including study participation, study attrition, prognostic factor measurement, outcome measurement, study confounding and statistical analysis and reporting [24]. Bias due to prognostic factor measurement was scored as moderate if it was not clear who performed the risk factor measurements. Bias due to confounding was scored as low if multivariate analysis was performed and as moderate in case of univariate analysis only (Table 2). 


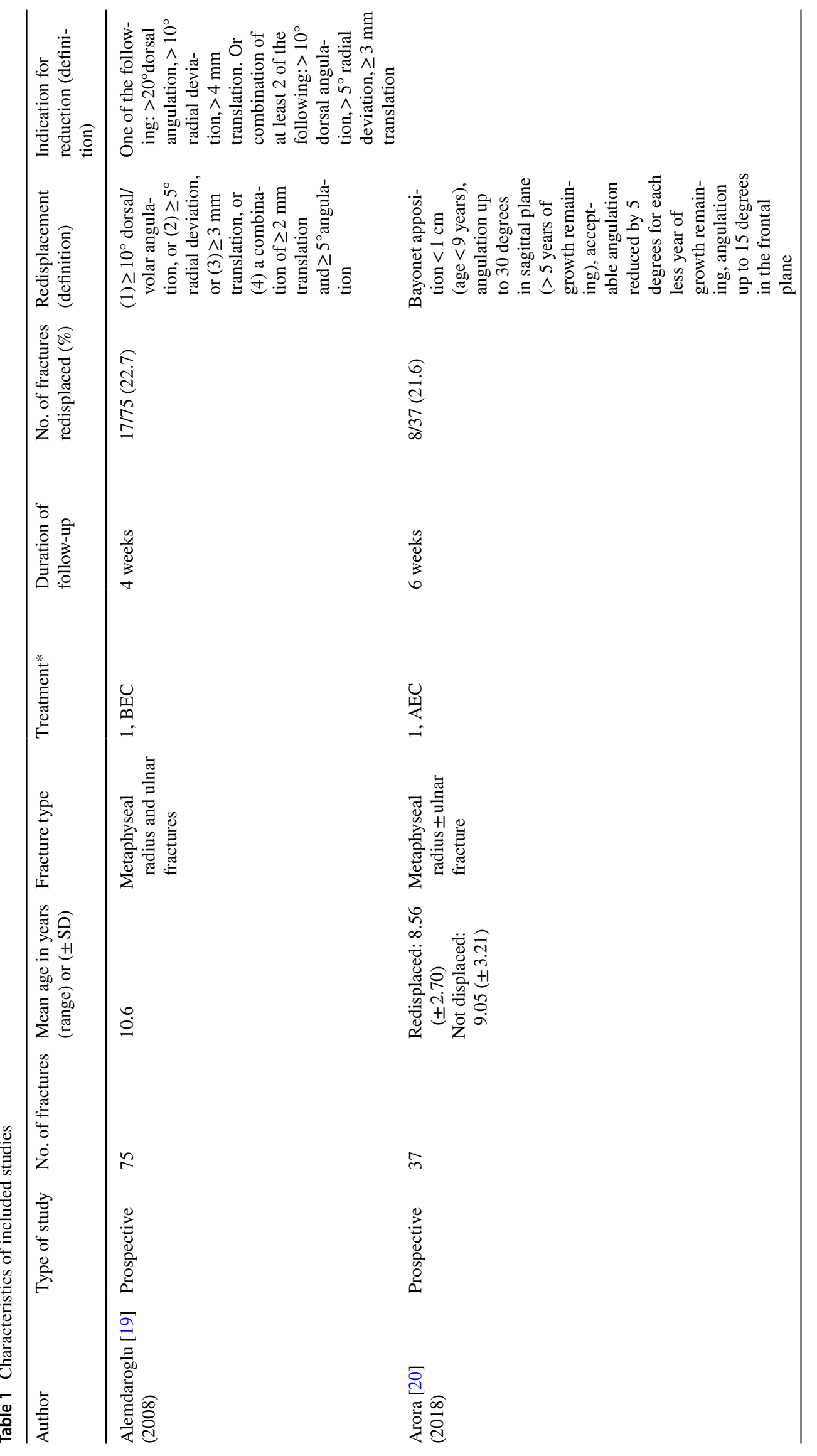




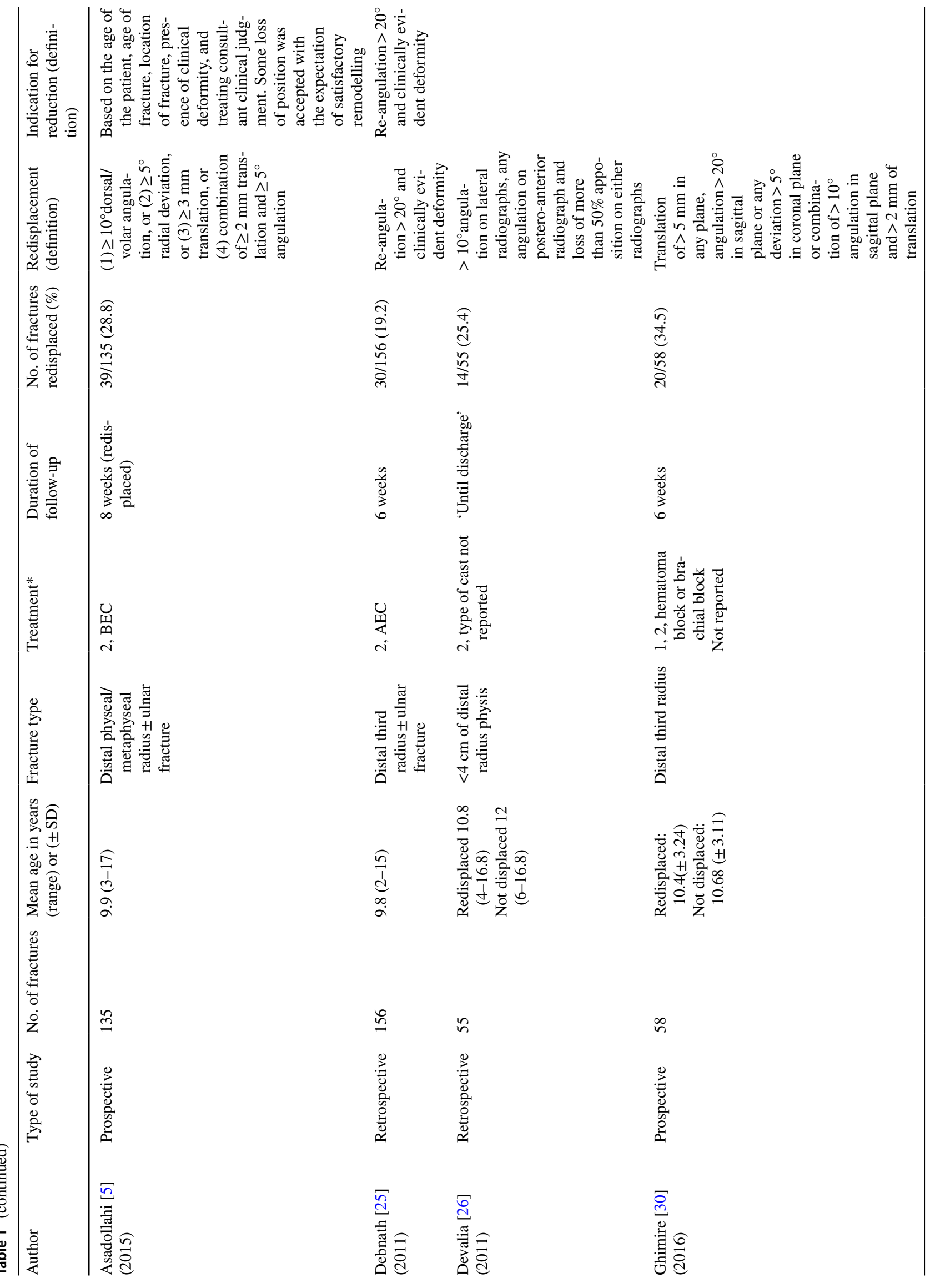




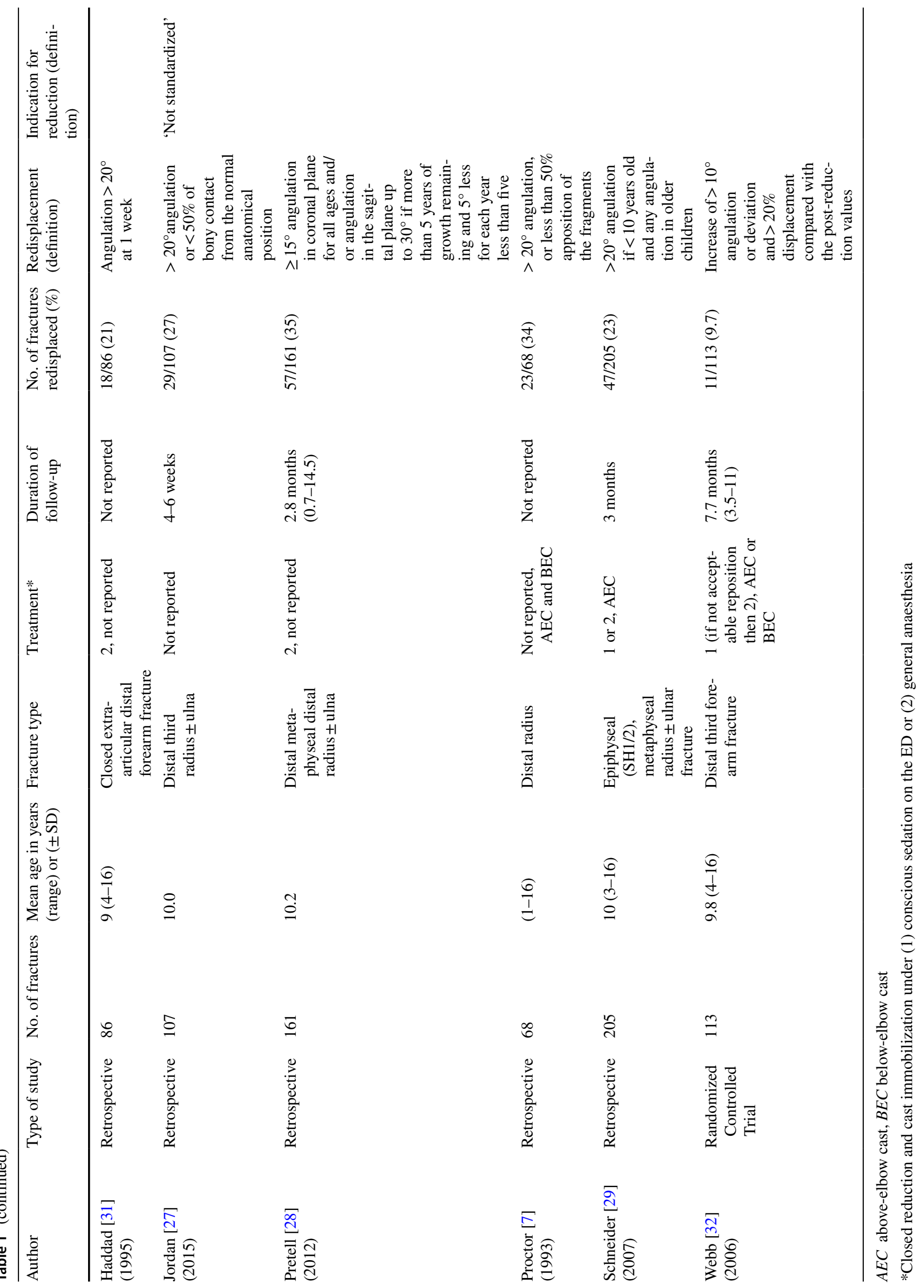




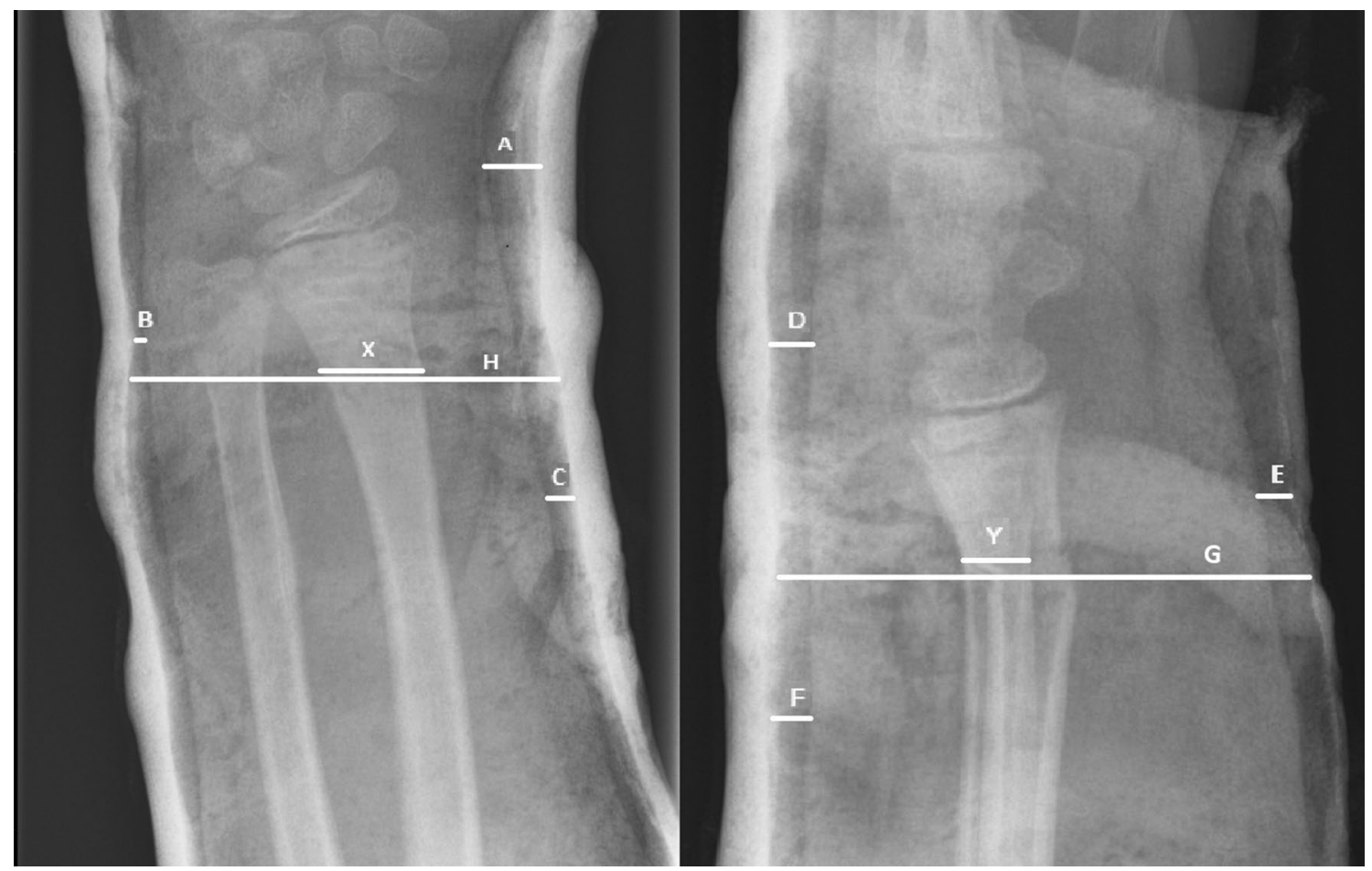

Fig. 1 Calculation of the Cast Index and Three-Point Index on the anteroposterior (on the left) and lateral (on the right) radiographs. The Cast Index is defined as the inner cast width at the fracture site on the lateral radiograph $(\mathbf{G})$ divided by the inner cast width on the anteroposterior radiograph $(\mathbf{H})$. The Three-Point Index is defined as $[(\mathrm{A}+\mathrm{B}+\mathrm{C}) / \mathrm{X}]+[\mathrm{D}+\mathrm{E}+\mathrm{F}) / \mathrm{Y}]$ with on the anteroposterior radiograph: $\mathbf{A}$ the narrowest radial-side gap between cast and skin around radiocarpal joint or scaphoid; $\mathbf{B}$ the narrowest ulnar side gap between cast and skin within $1 \mathrm{~cm}$ of the fracture; $\mathbf{C}$ the narrowest radial-side gap, 3-5 $\mathrm{cm}$ proximal to the fracture side. On the lateral radiograph, D the narrowest dorsal-side gap between skin and cast at radiocarpal joint or proximal carpal row; $\mathbf{E}$ and $\mathbf{F}$ similar to $\mathbf{B}$ and $\mathbf{C}$, however, at the volar- and dorsal-side gap, respectively, on the lateral radiograph $[5,18,19]$

Table 2 Quality of included studies according to the QUIPS tool

\begin{tabular}{|c|c|c|c|c|c|c|}
\hline Author & $\begin{array}{l}\text { Risk of bias due to } \\
\text { study participation }\end{array}$ & $\begin{array}{l}\text { Risk of bias due } \\
\text { to study attrition }\end{array}$ & $\begin{array}{l}\text { Risk of bias due to } \\
\text { prognostic factor meas- } \\
\text { urement }\end{array}$ & $\begin{array}{l}\text { Risk of bias due to } \\
\text { outcome measure- } \\
\text { ment }\end{array}$ & $\begin{array}{l}\text { Risk of bias due to } \\
\text { study confounding }\end{array}$ & $\begin{array}{l}\text { Risk of } \\
\text { bias due to } \\
\text { analysis }\end{array}$ \\
\hline Alemdaroglu [19] & Low & Low & Low & Low & Low & Low \\
\hline Arora [20] & Low & Low & Moderate & Low & Moderate & Low \\
\hline Asadollahi [5] & Low & Low & Low & Low & Low & Low \\
\hline Debnath [25] & Low & Low & Low & Low. & Moderate & Low \\
\hline Devalia [26] & Low & Low & Low & Low & Moderate & Low \\
\hline Ghimire [30] & Low & Low & Moderate & Low & Moderate & Low \\
\hline Haddad [31] & Low & Low & Moderate & Low & Moderate & Moderate \\
\hline Jordan [27] & Low & Low & Low & Low & Moderate & Low \\
\hline Pretell Mazzini [28] & Low & Moderate & Low & Low & Low & Low \\
\hline Proctor [7] & Low & Low & Low & Low & Low & Low \\
\hline Schneider [29] & Low & Low & Low & Low & Moderate & Low \\
\hline Webb [32] & Low & Low & Low & Low & Low & Low \\
\hline
\end{tabular}




\section{Results}

\section{Literature search}

The electronic search identified a total of 706 potentially eligible articles. After removal of duplicates, 285 articles remained and were screened for eligibility based on title and abstract. Fifty-seven articles were eligible and selected to read the full text. After screening the reference lists of these 57 articles, nine more potentially relevant studies were identified. Twelve articles that met the inclusion criteria and reported on similar age groups and definitions for redisplacement were included in this meta-analysis (Fig. 2) [5, 7, 18, 19, 25-32].

\section{Study characteristics}

Table 1 shows the characteristics of the twelve included studies. The studies were published between 1993 and 2018 and included a total of 1256 patients who received cast immobilization after reduction of a displaced distal radius fracture. Seven studies had a retrospective design, four a prospective design and one RCT was included.
Treatment consisted of reduction of the displaced fracture under conscious sedation on the ED, hematoma or brachial block, or general anaesthesia. Immobilization consisted of either an above- or below-elbow cast. The follow-up ranged between 1 and 7.7 months. Definitions for displacement and redisplacement are reported in Table $1[5,7,18,19,25-32]$.

\section{Outcome}

The mean follow-up ranged between 1 and 7.7 months. The overall redisplacement rate after initial reduction ranged from 9.7 to $35 \%$ [5, 7, 18, 19, 25-32]. Of all redisplaced fractures, 61\% (191/313) received secondary treatment.

\section{Risk factors}

Odds ratios were extracted or calculated from the 12 included studies. If insufficient data were available, corresponding authors were contacted. Asadollahi et al. supplied supplementary data [5]. The ORs were pooled for eight predictors (age, gender, isolated radius of a bothbone fracture, complete displacement, quality of reduction, Cast Index, Three-Point Index and surgeon's level of experience) for redisplacement in children after reduction

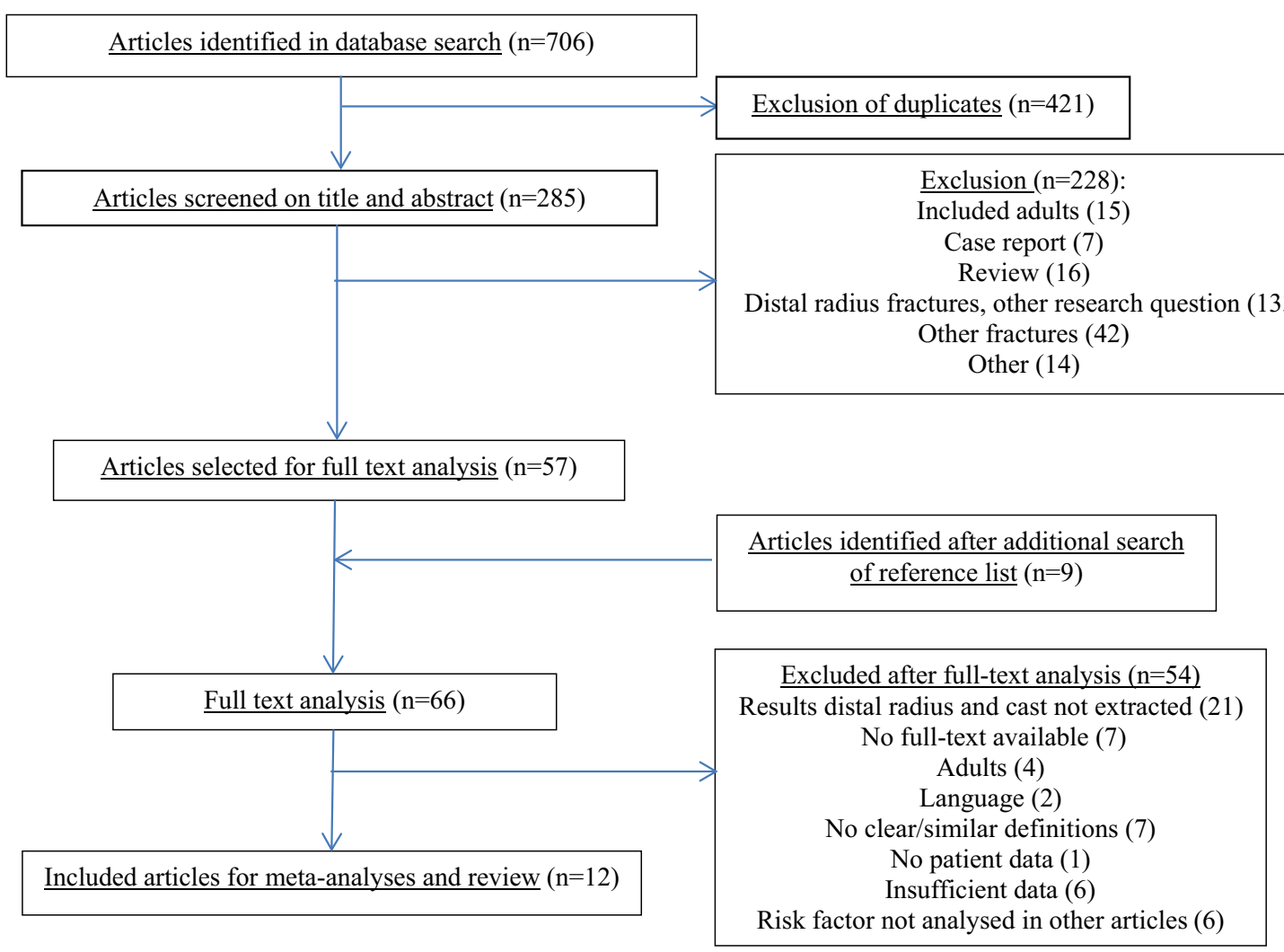

Fig. 2 Flowchart of included articles 
of a displaced distal radius fracture. Age $<10$ years vs $>10$ years (OR $1.11,95 \%$ CI $0.79-1.55)$ and female sex (OR 1.28, 95\% CI 0.83-1.97) were not significant risk factors for redisplacement (Figs. 3, 4). Complete displacement (mostly defined as one shaft width), when compared to incomplete displacement (OR 4.69, 95\% CI 2.98-7.39) and a both-bone fracture, when compared to an isolated radius fracture (OR 1.95, 95\% CI 1.34-2.85) were significant risk factors for redisplacement (Figs. 5, 6). Anatomic reduction significantly reduced the risk of redisplacement (OR 0.14, 95\% CI 0.05-0.40) when compared to non-anatomic reduction (Fig. 7). The Cast Index and Three-Point Index, both with optimal values considered below 0.8 , were not predictive for redisplacement (respectively, OR $0.45,95 \%$ CI $0.13-1.58$ and OR 0.33 , 95\% CI 0.01-16) (Figs. 8, 9) [5, 17-19, 27]. However, it should be noted that the results of the studies for both indexes were statistically heterogeneous $\left(\mathrm{I}^{2}>50 \%\right)$. The experience of the trainee/house officer compared to that of a senior registrar/consultant as the treating physician was also not a risk factor for redisplacement (OR 1.79, 95\% CI 0.68-4.72) (Fig. 10).

\begin{tabular}{|c|c|c|c|c|c|c|c|}
\hline Study or Subgroup & log[Odds Ratio] & SE & Weight & $\begin{array}{l}\text { Odds Ratio } \\
\text { IV, Random, } 95 \% \mathrm{Cl}\end{array}$ & & $\begin{array}{l}\text { Odds Ratio } \\
\text { IV, Random, } 95 \% \mathrm{Cl}\end{array}$ & \\
\hline Asadollahi & 0.0129 & 0.381 & $20.4 \%$ & $1.01[0.48,2.14]$ & & & \\
\hline Debnath & -0.3737 & 0.4131 & $17.4 \%$ & $0.69[0.31,1.55]$ & & & \\
\hline Pretell Mazzini & 0.1934 & 0.3364 & $26.2 \%$ & $1.21[0.63,2.35]$ & & & \\
\hline Proctor & 0.0362 & 0.5554 & $9.6 \%$ & $1.04[0.35,3.08]$ & & & \\
\hline Schneider & 0.4213 & 0.3344 & $26.5 \%$ & $1.52[0.79,2.94]$ & & 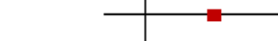 & \\
\hline Total $(95 \% \mathrm{Cl})$ & & & $100.0 \%$ & $1.11[0.79,1.55]$ & & & \\
\hline \multicolumn{5}{|c|}{$\begin{array}{l}\text { Heterogeneity: Tau }{ }^{2}=0.00 ; \mathrm{Chi}^{2}=2.38, \mathrm{df}=4(\mathrm{P}=0.67) ; \mathrm{I}^{2}=0 \% \\
\text { Test for overall effect: } Z=0.60(\mathrm{P}=0.55)\end{array}$} & 0.2 & $\begin{array}{l}0.5 \\
\leq 10 \text { years }>10 \text { years }\end{array}$ & 5 \\
\hline
\end{tabular}

Fig. 3 Risk of redisplacement in patients of below 10 years of age versus above 10 years

\begin{tabular}{|c|c|c|c|c|c|c|c|c|c|}
\hline Study or Subgroup & log[Odds Ratio] & SE & Weight & $\begin{array}{l}\text { Odds Ratio } \\
\text { IV, Random, } 95 \% \mathrm{Cl}\end{array}$ & & & $\begin{array}{l}\text { Odds Ratio } \\
\text { IV, Random, } 95 \% \mathrm{Cl}\end{array}$ & & \\
\hline Alemdaroglu & 1 & 0.935 & $5.6 \%$ & $2.72[0.43,16.99]$ & & & & & \\
\hline Arora & 0.7503 & 0.8993 & $6.1 \%$ & $2.12[0.36,12.34]$ & & & & & \\
\hline Asadollahi & 0.6419 & 0.4219 & $27.7 \%$ & $1.90[0.83,4.34]$ & & & & & \\
\hline Debnath & 0.0162 & 0.4591 & $23.4 \%$ & $1.02[0.41,2.50]$ & & & & & \\
\hline Devalia & -0.5008 & 0.7108 & $9.8 \%$ & $0.61[0.15,2.44]$ & & & & & \\
\hline Ghimire & -0.2877 & 0.7144 & $9.7 \%$ & $0.75[0.18,3.04]$ & & & & & \\
\hline Jordan & 0.2106 & 0.5289 & $17.6 \%$ & $1.23[0.44,3.48]$ & & & & & \\
\hline Total $(95 \% \mathrm{Cl})$ & & & $100.0 \%$ & $1.28[0.83,1.97]$ & & & & & \\
\hline \multicolumn{5}{|c|}{$\begin{array}{l}\text { Heterogeneity: } \text { Tau }^{2}=0.00 ; \mathrm{Chi}^{2}=3.76, \mathrm{df}=6(\mathrm{P}=0.71) ; \mathrm{I}^{2}=0 \% \\
\text { Test for overall effect: } Z=1.10(\mathrm{P}=0.27)\end{array}$} & 0.05 & 0.2 & Male ${ }^{1}$ Female & 5 & $\frac{1}{20}$ \\
\hline
\end{tabular}

Fig. 4 Risk of redisplacement in male versus female patients

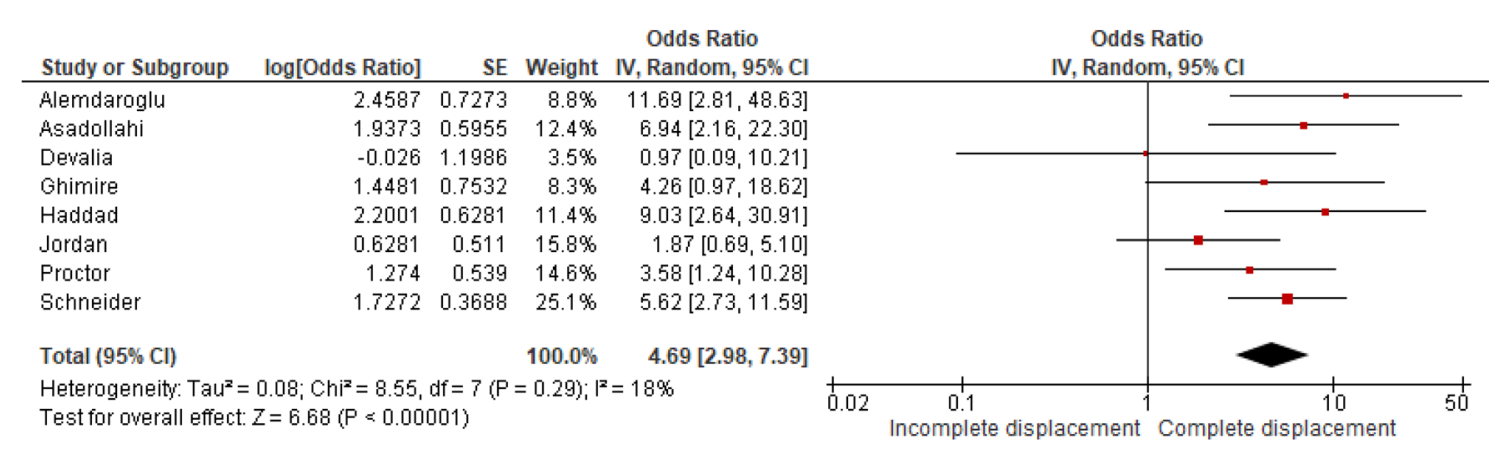

Fig. 5 Risk of redisplacement after incomplete versus complete displacement 


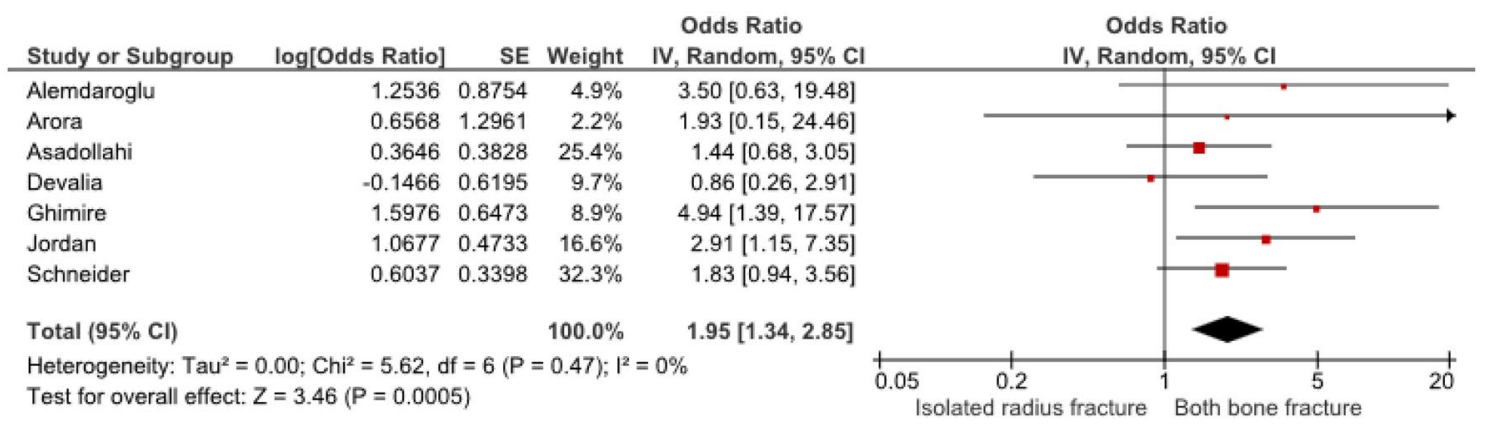

Fig. 6 Risk of redisplacement after isolated radius versus a both-bone fracture

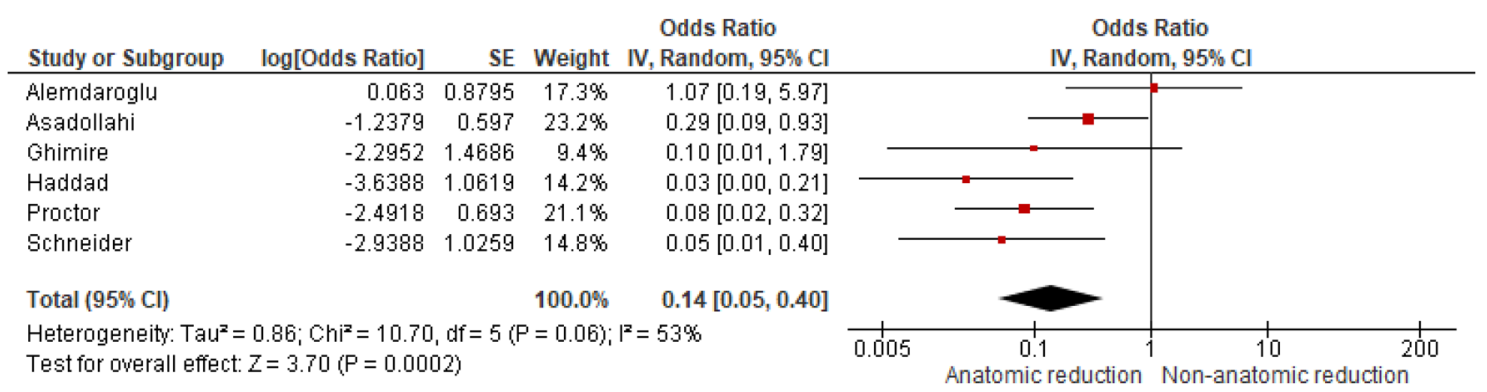

Fig. 7 Risk of redisplacement after anatomic reduction versus non-anatomic reduction

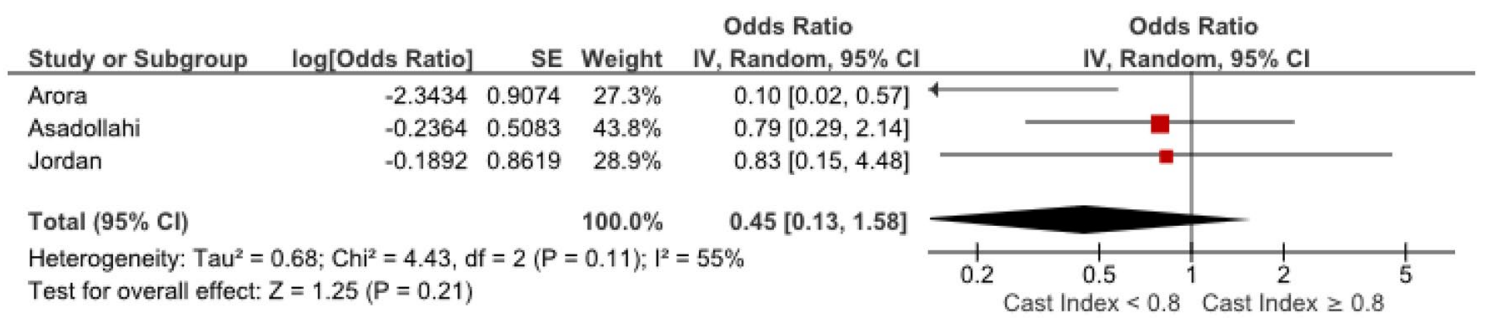

Fig. 8 Risk of redisplacement after Cast Index $<0.8$ versus Cast Index $>0.8$ on post-reduction radiograph

\begin{tabular}{|c|c|c|c|c|c|c|c|c|}
\hline Study or Subgroup & log[Odds Ratio] & SE & Weight & $\begin{array}{l}\text { Odds Ratio } \\
\text { IV, Random, } 95 \% \mathrm{Cl}\end{array}$ & & $\begin{aligned} O \\
\text { IV, } \\
\text { Ra }\end{aligned}$ & $\begin{array}{l}\text { Is Ratio } \\
\text { dom, } 95 \% \mathrm{Cl}\end{array}$ & \\
\hline Arora & -3.1987 & 1.165 & $47.0 \%$ & $0.04[0.00,0.40]$ & $4 \square$ & & & \\
\hline Asadollahi & 0.7608 & 0.6488 & $53.0 \%$ & $2.14[0.60,7.63]$ & & & & \\
\hline Total $(95 \% \mathrm{Cl})$ & & & $100.0 \%$ & $0.33[0.01,16.00]$ & & & & \\
\hline \multicolumn{5}{|c|}{$\begin{array}{l}\text { Heterogeneity: } \mathrm{Tau}^{2}=6.95 ; \mathrm{Chi}^{2}=8.82, \mathrm{df}=1(\mathrm{P}=0.003) ; \mathrm{I}^{2}=89 \% \\
\text { Test for overall effect: } \mathrm{Z}=0.56(\mathrm{P}=0.58)\end{array}$} & 0.01 & ${ }^{0.1} \mathrm{TPI}$ & $8^{1} \mathrm{TPI}>0.8^{10}$ & 100 \\
\hline
\end{tabular}

Fig. 9 Risk of redisplacement after Three-Point Index $<0.8$ versus Three-Point Index $>0.8$ on post-reduction radiograph

\section{Risk of bias}

The risk of bias of the included studies was low for almost all six domains (Table 2). Arora et al., Haddad et al. and
Ghimire et al. scored moderate on the risk of bias in the domain of prognostic factor measurement, because it was not reported who performed the measurements of the potential risk factors for redisplacement [19, 30, 31]. Many 


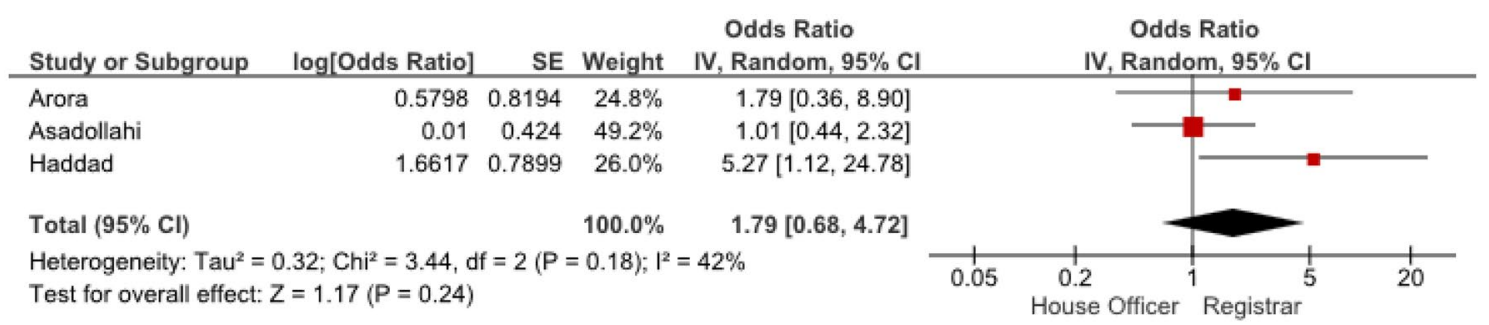

Fig. 10 Risk of redisplacement after treatment by a house officer versus registrar

of the included studies also scored moderate on biases in the domain of study confounding. This is because only univariate analysis was performed and no multivariate analysis [19, 25, 26, 29-31, 33].

\section{Discussion}

The aim of this meta-analysis was to identify the possible risk factors for redisplacement of distal radius fractures in children after reduction and cast immobilization and thereby determine which children benefit the most from additional $\mathrm{K}$-wire fixation after fracture reduction.

The results show that the presence of a both-bone fracture, initial complete displacement of the distal radius fragment and non-anatomical reduction are significant risk factors for redisplacement and, therefore, present as indications for reduction and additional primary K-wire fixation of paediatric displaced distal radius fractures.

Fracture-related factors are often studied as potential risk factors for redisplacement. Our results showed that it is important to achieve anatomic reduction to diminish the risk of redisplacement (OR 0.14, 95\% CI 0.05-0.40) (Fig. 7). One can imagine that achieving anatomical reduction is dependent on multiple other factors such as the experience of the treating physician and available resources (e.g. type of analgesics/sedatives, C-arm fluoroscopy) at the time of reduction. Nevertheless, the experience of the treating physician was not found to influence the risk of redisplacement (Fig. 10). This result is based on only three studies and could potentially be biased, as the trainee is often supervised by the attending senior/consultant. Furthermore, no difference was made between trainees with relatively little experience or multiple years of experience and between (orthopaedic) surgeons and emergency physicians. Despite this potential bias, Proctor et al. and Monga et al. found similar results $[7,34]$. One can also imagine that achieving anatomical reduction is more likely to be successful when there is a good understanding of the fracture mechanism; reduction takes place at the operating room, under conscious sedation or general anaesthesia and with the use of C-arm fluoroscopy. Unfortunately, there was insufficient information in the included articles to analyse whether or not these factors (i.e. type of anaesthesia, C-arm fluoroscopy) are of any influence on the risk of redisplacement. Three studies, not included in this meta-analysis, did report on these issues. Bear et al. compared haematoma block analgesia to procedural sedation and found no significant difference in radiographic alignment between groups. Moreover, haematoma block analgesia resulted in similar pain control, shorter duration of stay at the emergency department and comparable patient satisfaction as procedural sedation [35]. Luhmann et al. confirm these results in their study [36]. Lee et al. retrospectively analysed the use of C-arm fluoroscopy and showed that patients undergoing closed reduction with assistance of the mini C-arm fluoroscopy had significant improvement in quality of the reduction (average angulation in degrees \pm standard deviation; $6 \pm 4$ vs. $8 \pm 6 ; p=0.02$ ), less second reduction attempts and less need for operative treatment $(2 / 113$ vs. $14 / 166, p<0.0001)$ compared to reduction without the use of the C-arm fluoroscopy [37].

In 1994, Chess et al. introduced the Cast Index as an indicator for the quality of cast moulding. They described the quality of cast moulding as a risk factor for redisplacement after reduction of a paediatric displaced distal radius fracture [17]. Since then, more studies have been published about the quality of cast moulding and several other cast-related indices such as the Three-Point Index, Gap Index and Padding Index were analysed [5, 18, 19, 26, 38]. Unfortunately, the studies reporting the risk of redisplacement for all the different cast-related indices could not be combined in this meta-analysis since these indices provide heterogeneous outcomes. Based on the results of the three included papers that address this topic, the Cast Index and Three-Point Index do not seem to predict redisplacement after the first reduction in displaced distal radius fractures in children (Figs. 8, 9) [5, 15, 19]. More homogeneous studies are needed, however, to draw firm conclusions regarding the predictive value of cast-related indices since this potential risk factor can be positively influenced with little effort. After reduction and application of the cast, measurements on plain radiographs can be made and if needed, and the cast can be adjusted to reduce the risk of redisplacement. Even though the Cast Index is easier to measure, the Three-Point Index was found 
to be superior in predicting redisplacement when compared to the Cast Index (sensitivity $94.7 \%$, specificity $95.2 \%$, NPV 98.4\%, PPV $85.7 \%$ for Three-Point Index and sensitivity $63.2 \%$, specificity $52.4 \%$, NPV $82.5 \%$, PPV $28.6 \%$ for Cast Index) with high inter- and intra-observer reliability (intra class correlation coefficient 0.99$)[18,19]$. The studies included in the present meta-analysis reported redisplacement rates between $9.7 \%$ and $35 \%$ after reduction and cast immobilization of displaced distal radius fractures in children. Only $61 \%$ of the 313 redisplaced fractures received secondary treatment: 38 received repeat reduction and cast immobilization, 128 had additional $\mathrm{K}$-wire fixation after repeat reduction, 10 received ORIF, 1 received plate fixation and 3 patients received external fixation. Eighteen patients were reported to have had 'surgery, CRIF or ORIF' and for three patients, the cast was wedged as a secondary treatment. Fifty-eight (19.0\%) patients were considered to have enough potential for remodelling and received no further treatment after redisplacement. For the remaining $20.0 \%$ with a redisplaced fracture, it was not explicitly reported why secondary treatment was not deemed necessary. A reason might be that the definitions for redisplacement and the indications for secondary treatment were not similar in all studies. Also, wait and see policies are probably also based on the expectation that there is sufficient growth and the remodelling potential in the injured bone in children. Finally, the fact that an association of repeat reduction with growth disturbances and worse functional outcome has been described may have contributed to a reserved attitude towards repetitive reduction $[39,40]$.

This meta-analysis has several limitations. Although many studies have reported on the risk factors for redisplacement, only a few used similar indications for fracture reduction. This is partly due to the absence of globally accepted criteria for when to reduce a paediatric distal radius fracture. For all of the included articles, the criteria for redisplacement were angulation of at least 10 degrees, more than $2 \mathrm{~mm}$ translation or more than $20 \%$ of displacement when compared to post-reduction values. Furthermore, in current decision-making on fracture reduction in children, the potential for remodelling in relation to the acceptable amount of displacement is not adequately incorporated. This is also shown in the included articles, as only three out of twelve reported on criteria for reduction that were specified by the age of the patient and thereby the expected remodelling potential (Table 1). Younger children have a greater spontaneous remodelling potential and, therefore, for them, larger amounts of displacement can be accepted without reduction and immobilization (cast and/or K-wire fixation). In practice, this should be considered not only before primary reduction but also if redisplacement occurs. However, including this information in our analysis would be difficult since remodelling not only depends on age but also, for example, on race and sex. Despite helpful AO guidelines, the definitions for redisplacement, indications for fracture reduction and inadequate incorporation of the potential for remodelling differed between the studies. This could potentially lead to over- or underestimation of the true redisplacement risk when applying our results to future patients.

No statistical heterogeneity in study results for the risk factors was found, except for analysis of the Cast Index, Three-Point Index and quality of reduction $\left(\mathrm{I}^{2}>50 \%\right)$.

A third limitation is the heterogeneous presentation of other potential predictors for redisplacement. This includes several cast-related indices, comminution of the fracture and distance of the fracture to the physis that could be related to redisplacement after reduction of a fracture. Unfortunately, due to the heterogeneous data, these potential predictors could not be included in this meta-analysis.

This meta-analysis shows that for children with a displaced distal radius fracture, the presence of a both-bone fracture, complete displacement of the distal radius and non-anatomical fracture reduction are risk factors for redisplacement of their initially displaced distal radius fracture. Children with one or more of these risk factors will probably benefit most of the reduction combined with primary $\mathrm{K}$-wire fixation.

\section{Compliance with ethical standards}

Conflict of interest A. Sengab, P. Krijnen, and I.B. Schipper declare that they have no conflict of interest.

Research involving human participants and/or animals This article does not contain any studies with human participants performed by any of the authors.

Informed consent This article does not contain any studies with human participants performed by any of the authors.

Open Access This article is distributed under the terms of the Creative Commons Attribution 4.0 International License (http://creativeco mmons.org/licenses/by/4.0/), which permits unrestricted use, distribution, and reproduction in any medium, provided you give appropriate credit to the original author(s) and the source, provide a link to the Creative Commons license, and indicate if changes were made.

\section{References}

1. Cheng JC, Shen WY. Limb fracture pattern in different pediatric age groups: a study of 3,350 children. J Orthop Trauma. 1993;7(1):15-22.

2. Worlock P, Stower M. Fracture patterns in Nottingham children. J Pediatr Orthop. 1986;6(6):656-60.

3. Rennie $\mathrm{L}$, et al. The epidemiology of fractures in children. Injury. 2007;38(8):913-22.

4. Landin LA. Epidemiology of children's fractures. J Pediatr Orthop B. $1997 ; 6(2): 79-83$. 
5. Asadollahi S, Ooi KS, Hau RC. Distal radial fractures in children: risk factors for redisplacement following closed reduction. J Pediatr Orthop. 2015;35(3):224-8.

6. Marcheix PS, et al. Dorsal distal radius fractures in children: role of plaster in redisplacement of these fractures. J Pediatr Orthop B. 2011;20(6):372-5.

7. Proctor MT, Moore DJ, Paterson JM. Redisplacement after manipulation of distal radial fractures in children. J Bone Joint Surg Br. 1993;75(3):453-4.

8. McQuinn AG, Jaarsma RL. Risk factors for redisplacement of pediatric distal forearm and distal radius fractures. J Pediatr Orthop. 2012;32(7):687-92.

9. Zamzam MM, Khoshhal KI. Displaced fracture of the distal radius in children: factors responsible for redisplacement after closed reduction. J Bone Joint Surg Br. 2005;87(6):841-3.

10. McLauchlan GJ, et al. Management of completely displaced metaphyseal fractures of the distal radius in children. A prospective, randomised controlled trial. J Bone Joint Surg Br. 2002;84(3):413-7.

11. Choi KY, et al. Percutaneous Kirschner-wire pinning for severely displaced distal radial fractures in children. A report of 157 cases. J Bone Joint Surg Br. 1995;77(5):797-801.

12. Gibbons CL, et al. The management of isolated distal radius fractures in children. J Pediatr Orthop. 1994;14(2):207-10.

13. Mostafa MF, El-Adl G, Enan A. Percutaneous Kirschner-wire fixation for displaced distal forearm fractures in children. Acta Orthop Belg. 2009;75(4):459-66.

14. Horii E, et al. Premature closure of the distal radial physis. J Hand Surg Br. 1993;18(1):11-6.

15. Jordan RW, Westacott DJ. Displaced paediatric distal radius fractures-when should we use percutaneous wires? Injury. 2012;43(6):908-11.

16. Luscombe KL, et al. Selective Kirschner wiring for displaced distal radial fractures in children. Acta Orthop Traumatol Turc. 2010;44(2):117-23.

17. Chess DG, et al. Short arm plaster cast for distal pediatric forearm fractures. J Pediatr Orthop. 1994;14(2):211-3.

18. Alemdaroglu KB, et al. Risk factors in redisplacement of distal radial fractures in children. J Bone Joint Surg Am. 2008;90(6):1224-30.

19. Arora R, et al. Factors responsible for redisplacement of pediatric forearm fractures treated by closed reduction and cast: role of casting indices and three point index. Indian J Orthop. 2018;52(5):536-47.

20. Moher D, et al. Preferred reporting items for systematic reviews and meta-analyses: the PRISMA statement. Int J Surg. 2010;8(5):336-41.

21. Hendrickx RP, et al. Above- or below-elbow casts for distal third forearm fractures in children? A meta-analysis of the literature. Arch Orthop Trauma Surg. 2011;131(12):1663-71.

22. van den Bekerom MP, Hendrickx RH, Struijs PA. Above- or below-elbow casts for distal third forearm fractures in children? An updated meta-analysis of the literature. Arch Orthop Trauma Surg. 2012;132(12):1819-20.
23. Bown MJ, Sutton AJ. Quality control in systematic reviews and meta-analyses. Eur J Vasc Endovasc Surg. 2010;40(5):669-77.

24. Hayden JA, et al. Assessing bias in studies of prognostic factors. Ann Intern Med. 2013;158(4):280-6.

25. Debnath UK, Guha AR, Das S. Distal forearm fractures in children: cast index as predictor of re-manipulation. Indian J Orthop. 2011;45(4):341-6.

26. Devalia KL, Asaad SS, Kakkar R. Risk of redisplacement after first successful reduction in paediatric distal radius fractures: sensitivity assessment of casting indices. J Pediatr Orthop B. 2011;20(6):376-81.

27. Jordan RW, et al. Predicting redisplacement after manipulation of paediatric distal radius fractures: the importance of cast moulding. Eur J Orthop Surg Traumatol. 2015;25(5):841-5.

28. Pretell MJ, et al. Distal metaphyseal radius fractures in children following closed reduction and casting: can loss of reduction be predicted? Int Orthop. 2012;36(7):1435-40.

29. Schneider J, et al. Treating displaced distal forearm fractures in children. Eur J Trauma Emerg Surg. 2007;33(6):619-25.

30. Ghimire N, Uprety S, Lamichhane A. Risk factors for redisplacement in pediatric distal radius fractures after closed reduction and cast immobilisation. J Inst Med. 2016;38(1):81-4.

31. Haddad FS, Williams RL. Forearm fractures in children: avoiding redisplacement. Injury. 1995;26(10):691-2.

32. Webb GR, Galpin RD, Armstrong DG. Comparison of short and long arm plaster casts for displaced fractures in the distal third of the forearm in children. J Bone Joint Surg Am. 2006;88(1):9-17.

33. Jordan RW, et al. A comparison of ketamine sedation and general anaesthesia for manipulation of paediatric forearm fractures. Acta Orthop Belg. 2016;82(4):836-42.

34. Monga P, Raghupathy A, Courtman NH. Factors affecting remanipulation in paediatric forearm fractures. J Pediatr Orthop B. 2010;19(2):181-7.

35. Bear DM, et al. Hematoma block versus sedation for the reduction of distal radius fractures in children. J Hand Surg Am. 2015;40(1):57-61.

36. Luhmann JD, et al. A randomized comparison of nitrous oxide plus hematoma block versus ketamine plus midazolam for emergency department forearm fracture reduction in children. Pediatrics. 2006;118(4):e1078-86.

37. Lee MC, et al. Mini-C-arm fluoroscopy for emergency-department reduction of pediatric forearm fractures. J Bone Joint Surg Am. 2011;93(15):1442-7.

38. Hang JR, Hutchinson AF, Hau RC. Risk factors associated with loss of position after closed reduction of distal radial fractures in children. J Pediatr Orthop. 2011;31(5):501-6.

39. Lee BS, Esterhai JL Jr, Das M. Fracture of the distal radial epiphysis. Characteristics and surgical treatment of premature, post-traumatic epiphyseal closure. Clin Orthop Relat Res. 1984;185:90-6.

40. Zimmermann R, et al. Late sequelae of fractures of the distal third of the forearm during the growth period. Handchir Mikrochir Plast Chir. 2000;32(4):242-9. 